Controlling Radiated Emissions by Design 

Michel Mardiguian

\section{Controlling Radiated Emissions by Design}

Third Edition

With contributions from Donald L. Sweeney and Roger Swanberg

望 Springer 
Michel Mardiguian

EMC Consultant

St Remy-les-Chevreuse, France

ISBN 978-3-319-04770-6

ISBN 978-3-319-04771-3 (eBook)

DOI 10.1007/978-3-319-04771-3

Springer Cham Heidelberg New York Dordrecht London

Library of Congress Control Number: 2014933797

(C) Springer International Publishing Switzerland 2014

This work is subject to copyright. All rights are reserved by the Publisher, whether the whole or part of the material is concerned, specifically the rights of translation, reprinting, reuse of illustrations, recitation, broadcasting, reproduction on microfilms or in any other physical way, and transmission or information storage and retrieval, electronic adaptation, computer software, or by similar or dissimilar methodology now known or hereafter developed. Exempted from this legal reservation are brief excerpts in connection with reviews or scholarly analysis or material supplied specifically for the purpose of being entered and executed on a computer system, for exclusive use by the purchaser of the work. Duplication of this publication or parts thereof is permitted only under the provisions of the Copyright Law of the Publisher's location, in its current version, and permission for use must always be obtained from Springer. Permissions for use may be obtained through RightsLink at the Copyright Clearance Center. Violations are liable to prosecution under the respective Copyright Law.

The use of general descriptive names, registered names, trademarks, service marks, etc. in this publication does not imply, even in the absence of a specific statement, that such names are exempt from the relevant protective laws and regulations and therefore free for general use.

While the advice and information in this book are believed to be true and accurate at the date of publication, neither the authors nor the editors nor the publisher can accept any legal responsibility for any errors or omissions that may be made. The publisher makes no warranty, express or implied, with respect to the material contained herein.

Printed on acid-free paper

Springer is part of Springer Science+Business Media (www.springer.com) 


\section{Foreword to the First Edition}

Something over a year ago, I was fortunate enough to preview another VNR book, Controlling Conducted Emissions by Design, by John Fluke. My assessment at the time was that Mr. Fluke had written a very good and useful volume, its only flaw being that it focused on just half of the EMI emissions problem. This, of course, was also its strength; although radiated and conducted emissions do not exist in separate worlds, it can be useful, at least as a point of departure, to look at them as distinct phenomena. Expanding the scope of the conducted emissions book therefore would have served mostly to dilute its purpose and compromise its clarity.

After some informal discussions with the publisher on that subject, it was decided to correct the sin of omission by recruiting an author for a companion volume, to be titled Controlling Radiated Emissions by Design. I am gratified to have played a minor role in making that happen.

Many EMC engineers with whom I have worked over the years are capable of writing a good radiated emissions book, but few can match Michel Mardiguian's combination of practical engineering experience and proficiency with the pen. On the engineering side, he has worked on such diverse projects as the Mirage $\mathrm{V}$ vertical takeoff jet fighter, computer-controlled PBX systems, and, most recently, the renowned tunnel that stretches beneath the English Channel to join England with France.

In terms of academic credentials, the author has written or coauthored at least half a dozen earlier books, including a highly durable and well-respected one on electrostatic discharge. He has taught the principles of electromagnetic compatibility throughout the USA and Europe, and IEEE symposium records contain many of his short works.

Michel's books typically have several characteristics:

1. They are aimed at practical applications but provide enough theoretical material to support the suggested design and retrofit solutions.

2. They rely heavily on visual material, allowing the reader to "see" the EMI problems and solutions.

3. They omit everything that is not essential to the subject under scrutiny. 
This third quality is less common that one might expect-many authors feel an irresistible urge to stuff everything they know into one volume. But Michel avoids egocentric dissertations on marginal subjects, preferring to approach each book simply as a job that needs to be done.

With this book, the author follows his usual pattern but with perhaps a greater refinement. Mathematical material is largely confined to two chapters, allowing the book to look mostly at real-world applications. More than 175 tables and illustrations provide information in a highly accessible format. This type of book is difficult for the editors and expensive for the publisher, but the reader should benefit. Some subjects (e.g., EMC testing) are covered very briefly, but the reader is referred to other sources of pertinent information.

It would be premature and presumptuous to call this book a classic in EMC literature, but it does display some of the characteristics of enduring works. Controlling Radiated Emissions by Design constitutes a cohesive and clear examination of the subject and is perhaps the author's best work to date.

Gainesville, VA

Jeffrey K. Eckert

1992 


\section{Preface}

Back in 1992, I was teaching an in-house EMC seminar at a major manufacturing facility and my students were so interested to learn more; they wanted me to extend the class. My search for more material led me to Michel Mardiguian's new book, the first edition of Controlling Radiated Emissions by Design, and I've included it and its second edition in my seminars ever since. There are several reasons for this.

First is that the goal of my seminar is to help students think through designing an EMC compliant product from the beginning to the end, and this is exactly what Michel's book does. It starts by explaining why we need to understand the problems of radiation and how radiation happens, along with some simple mathematics for predicting the emissions and harmonic content. Michel uses graphs to further simplify the calculations. He then discusses the strategy for designing a low radiated emission product, both in the choice of circuit technology and circuit board design and all the decisions one needs to make when beginning a design. He then shows how to minimize emissions from cables and packaging. He next develops shielding, including predicting leakage from various types of apertures with real-life examples, using the emissions already predicted from our circuits in the book. He then concludes the book by showing how to troubleshoot a product when it doesn't comply with its emission requirements, including the use of a current probe to predict the reduction in emissions.

Michel is a practitioner, one who actually uses what he writes about in his consulting practice. This gives the reader a process that he/she can use to expand themselves in the field of EMC.

Secondly, instead of ending a chapter by providing problems for the student to figure out on their own, Michel gives sample problems within the text and shows step-by-step solutions to them. Our students have found the procedures and equations developed in the book so beneficial that we have developed several computer programs which allow the design engineers to repeat the calculations quickly and repeatably as they are designing their product.

Thirdly, Michel explains EMC design concepts that are easy to understand and to follow. After developing the EMC concepts, he intersperses practical examples 
allowing the students to use what they just learned. These examples are rare in textbooks.

I use Michel's book during my class to supplement my own teaching materials, and I also give each of my students a copy of the book for later reference. It is also an excellent book for individual use outside the classroom.

After teaching, I give students an opportunity to sit down with an EMC expert and discuss one-on-one their own product or concerns. While doing so, one student once said, "I would not even have understood what you are talking about had I not just taken your class. Now I see what we have been doing wrong." What more needs to be said about Michel's book, seeing how it affected this student and many others like him!

Michel Mardiguian has had a distinguished career with extensive EMC experience working in the honored positions of IBM EMC Specialist, French Delegate to the CISPR Group on Computer RFI, and Director of Training for Don White Consultants. He has written many widely read books and articles and has given many lectures on EMC topics. In 2007, he received the IEEE EMC Society's prestigious Technical Achievement Award.

Wheeling, IL

Donald L Sweeney

October 2013 


\section{Acknowledgements}

It would be unfair and incomplete if full credit was not given to those who helped with the birth of this book, and constantly attended its writing and proofing. Of all these devoted contributors, the prominent one is certainly Donald Sweeney, who relentlessly, in December 2012, inspired me to write this third edition. Don struggled eagerly through every paragraph and chapter, for the best comprehension and consistency of what I was trying to say. His colleagues at D.L.S., Roger Swanberg, Tim Lusha, and Corey Sweeney made a definite contribution to the contents of the chapters dealing with International RFI regulations and measurement procedures. Bill Stumpf and Steve Grimes did the edit review of the standards material, while Mark Rozema, Jack Prawica, and Jereme Irwin reviewed the military and RTCA part as well as Paul Vicory reviewing the automotive sections. Last but not least, I am indebted to the ladies at D.L.S.: Jessica Stephens, who did the artwork, tables, website, extensive editing, and overall support; Maxine Martin who carefully checked and rewrote some material, including those parts where Don and myself were fighting over some language controversy; Marilyn Sweeney who edited Chap. 1; and Carol Pittl who did the editing and scanning of several parts.

Michel Mardiguian 



\section{Contents}

1 Generalities on Radiated Interference . . . . . . . . . . . . 1

1.1 The Problem of Radiated EMI . . . . . . . . . . . . . . . 1

1.2 Basic Understanding of Radiated EMI . . . . . . . . . . . 2

1.3 EMI Terminology and Units . . . . . . . . . . . . 4

1.4 The USA and Worldwide Regulatory Approach

1.4.1 Worldwide Civilian Standards . . . . . . . . . . . . . . 6

1.4.2 FCC Standards for Emissions . . . . . . . . . . . . . . 10

1.4.3 The Mutual Recognition Agreement (MRA) . . . . . . . . 11

1.4.4 Other US Government Standards (Nonmilitary) . . . . . . . 11

1.4.5 Military Emission Standards . . . . . . . . . . . . . . . . 12

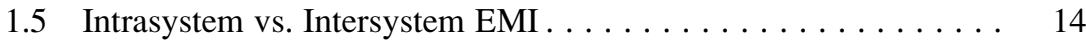

2 Electric and Magnetic Fields from Simple Circuit Shapes . . . . . . 17

$2.1 \quad$ Field Radiated by a Loop . . . . . . . . . . . . . . . . 18

2.2 Fields Radiated by a Straight Wire . . . . . . . . . . . 21

2.3 Extension to Practical, Real-Life Circuits . . . . . . . . . . 24

2.3.1 Fields Radiated by Actual Conductor Pairs . . . . . . . . 25

2.3.2 Fields Radiated by a Wire or Trace Above a Ground Plane.................... 30

2.4 Differential-Mode Radiation from Simple Circuits . . . . . . . . 31

2.5 Common-Mode Radiation from External Cables . . . . . . . . . . 34

2.5.1 How to Estimate CM Currents on Cables . . . . . . . . . . 37

2.5.2 Approximating the Proper Radiating Geometry . . . . . . 40

2.5.3 Radiation from a Long Wire . . . . . . . . . . . 50

References........................... 51

3 Fields Radiated by Nonsinusoidal Sources . . . . . . . . . . . . . . 53

3.1 Frequency Spectrum and Radiation from Periodic Pulses . . . . . 53

3.2 Spectrum and Radiation from Broadband Sources . . . . . . . . . 60

3.3 Random vs. Periodic Spectra . . . . . . . . . . . . . . 66 
3.4 Peculiar Aspects of Some Frequency Spectra . . . . . . . . . . . 67

3.4.1 Random Signals with Narrowband Contents . . . . . . . . . 68

3.4.2 Repetitive Symbols Enhancing EMI Radiations . . . . . . . 70

3.4.3 Spread Spectrum Clocks (SSC) for Reduced EMI . . . . . 70

3.4.4 Even vs. Odd harmonics when Duty Cycle Is Not

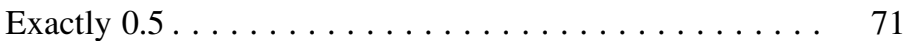

References........................... 74

4 General Strategy for Designing a Low-Radiation Product . . . . . . 75

4.1 Basic System Decisions that Impact EMI Control . . . . . . . . 75

4.2 Design Control Areas for Radiated Emission Reduction . . . . . . 77

4.3 Design Milestones for Radiated EMI Control . . . . . . . . . . . 79

4.3.1 Radiation from Differential-Mode (DM) Loops . . . . . . . 79

4.3.2 Radiation from Common-Mode (CM) Excitation ....... 81

4.4 Influence of the Resident Software on Radiated EMI . . . . . . . . 83

References............................... 84

\section{Controlling Radiated Emissions at Chip and Integrated}

Circuit Level . . . . . . . . . . . . . . . . . . . . . 85

$5.1 \quad$ Logic Families . . . . . . . . . . . . . . . . . . . 85

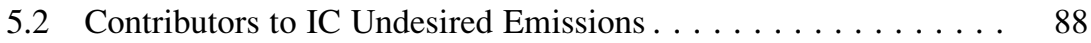

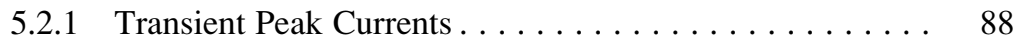

5.2.2 Fields Radiated by the IC Alone . . . . . . . . . . . . 90

5.2.3 Generation of Common-Mode Noise by IC

Ground Bounce..................... 96

5.2.4 Low-Voltage Differential Logic, Benefits, and Problems...................... 98

5.3 Calculating the Ideal Bypass Capacitor . . . . . . . . . . 101

5.4 Reducing EMI Generation at the IC Itself . . . . . . . . . . 103

5.4.1 EMI Quiet Microprocessors and Fast ICs . . . . . . . . . . 103

5.4.2 Advantages with "3-D" Packaging . . . . . . . . . . . . . . 104

5.4.3 EMI Contribution of Clock Oscillators . . . . . . . . . 105

5.4.4 Simulation Software for IC Emissions . . . . . . . . . . . . 105

5.5 Standard Methods for IC Emissions Measurements . . . . . . . . . . 107

5.6 Influence of the IC Package on Radiated Emissions . . . . . . . 110

5.7 Shielding at the IC Level . . . . . . . . . . . . . . . . 112

5.8 Summary of Radiation Control Hints at the Chip and IC Level . . . . . . . . . . . . . . . . . . . . . . . . . 114

References........................... 115

6 Printed Circuit Board Design . . . . . . . . . . . . . . . . . . . . . 117

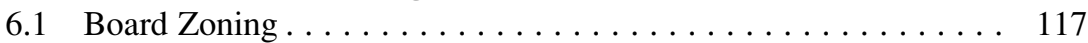

6.2 Brushup on Self-Inductance of Conductors and Planes . . . . . . . 118

6.2.1 Inductance and Impedance of Wires and Traces . . . . . . . 118

6.2.2 Inductance and Impedance of Planes . . . . . . . . . . . . 119

6.2.3 Parasitic Radiation by a Finite PCB Ground Plane ... . . . 122 
6.3 Single-Layer, One- and Two-Sided Boards . . . . . . . . . . . . . 124

6.3.1 Power Supply Distribution and Decoupling with Single Layers . . . . . . . . . . . . . . . . . . . 124

6.3.2 The Problem with Bypass Capacitors in Parallel . . . . . . 129

6.3.3 Decoupling at the Board Power Input . . . . . . . . . . . 130

6.3.4 $\mathrm{V}_{\mathrm{cc}}$ and Ground Traces Layout (One-Sided, Single-Layer Board) . . . . . . . . . . . . . . . 131

6.3.5 The Need for Ground Planes and Ground Areas (Single-Layer Board) . . . . . . . . . . . . . . . . . . 131

6.3.6 Trace-to-Chassis Parasitic Coupling . . . . . . . . . . . . . 134

6.3.7 Clock Traces (Single-Layer Boards) . . . . . . . . . . . . 135

6.4 Multilayer Boards . . . . . . . . . . . . . . . . . . 135

6.4 .1 Multilayer Stacking . . . . . . . . . . . . . . . . . 138

6.4.2 Decoupling Capacitor Requirements with Multilayers . . . . . . . . . . . . . . . . . . . 141

6.4.3 Perforated Planes: The Swiss Cheese Syndrome . . . . . . 143

6.4 .4 Allowable Slots . . . . . . . . . . . . . . . . . . . . 143

6.4.5 Placement of High-Speed Traces . . . . . . . . . . . . . 145

6.4.6 Analog/Digital Mix . . . . . . . . . . . . . . . . . . . 145

6.4 .7 Thin Foil PCBs . . . . . . . . . . . . . . . . . . . . . . . . 149

6.5 Crosstalk Contribution to Radiated EMI . . . . . . . . . . . . . . . . 149

6.5.1 Capacitive Crosstalk . . . . . . . . . . . . . . . 150

6.5.2 Magnetic Crosstalk . . . . . . . . . . . . . . . . . . 155

6.5.3 Combined Effects of Capacitive and Magnetic Crosstalk . . . . . . . . . . . . . . 157

$6.6 \quad$ Impedance Matching . . . . . . . . . . . . . . . . . . . . . 158

6.6.1 Parasitic Oscillations with Mismatched Lines . . . . . . . 158

6.6.2 EMI Concerns with Impedance Mismatch

at PCB Vias Transitions . . . . . . . . . . . . . . 161

6.7 PCB Connector Pin Assignment . . . . . . . . . . . . . . . . . . 161

6.7.1 Crosstalk in Connectors . . . . . . . . . . . . . . . . . 162

6.7.2 Connector Characteristic Impedance and Mismatch . . . . . . . . . . . . . . . . . . . . 162

6.7 .3 Contacts Impedance . . . . . . . . . . . . . . . . . . . 164

6.8 Grounding of $0 \mathrm{~V}$ Reference to Chassis . . . . . . . . . . . . 165

6.9 EMC Software Tools for PCB Designs . . . . . . . . . . . . . . . 167

6.10 Summary of Radiation Control at PCB Level . . . . . . . . . . . . 168

References... . . . . . . . . . . . . . . . . . . . . . 169

7 Emission Control in Motherboards and Backplanes . . . . . . . . . . . 171

$7.1 \quad$ Wire-Wrapped Backplanes . . . . . . . . . . . . . . . 173

7.2 Single or Multilayer Motherboards with

$\mathrm{V}_{\mathrm{cc}}$ /Ground Planes . . . . . . . . . . . . . . . . . 173

7.3 Crosstalk and Impedance Matching . . . . . . . . . . . . . 173

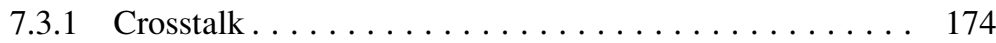

7.3 .2 Impedance Matching . . . . . . . . . . . . . . . . 174 
7.4 Connector Areas at Backplane Interfaces . . . . . . . . . . . . . . . 175

7.5 Increased Radiation in Connectors Areas . . . . . . . . . . . . . . 176

8 Controlling Radiated Fields from Switch-Mode

Power Supplies . . . . . . . . . . . . . . . . . . . . . . . . . . 177

$8.1 \quad$ Basic Radiating Sources . . . . . . . . . . . . . . . . . . . 177

8.2 Effect of Actual Current Waveforms . . . . . . . . . . . 181

$8.3 \quad$ Packaging and Circuit Layout . . . . . . . . . . . . . 182

8.3.1 Magnetic Leakages from Transformers

and Chokes . . . . . . . . . . . . . . . . . . . . . 183

8.3.2 The Power Supply PC Board . . . . . . . . . . . . . . . . . . . . . . . . . 183

8.3 .3 Secondary Loops . . . . . . . . . . . . . . . . . . . . . . . 184

8.3.4 Electromechanical Packaging . . . . . . . . . . . . . 186

$8.4 \quad$ Shielding the Power Supply Module . . . . . . . . . . . . . . . . 189

8.5 Effect of the Power Supply Filter on Radiated EMI . . . . . . . 190

8.6 EMI Radiation from Small DC-DC Modules . . . . . . . . . . . . 195

References.............................. 196

9 Reducing Radiated EMI Via Internal Cabling and Packaging . . . . 197

9.1 Card-to-Card and Backplane Interconnects . . . . . . . . . . . . 197

9.2 Internal Wiring Rules Between Subunits . . . . . . . . . . . . . . 199

9.2.1 General Rules for Ordinary, Unshielded Cables . . . . . . 199

9.2.2 Coaxial Cables....................... 201

9.2.3 Internal Shielded Cables, Other Than Coaxial . . . . . . 202

9.3 Some Hidden Radiating Antennas . . . . . . . . . . . . . . . 203

9.4 Internal Connection of $0 \mathrm{~V}$ Reference and Corresponding Ground Loops . . . . . . . . . . . . . . . 206

9.5 Packaging Precautions at I/O Connector Areas . . . . . . . . . . . . . 208

9.6 A Few Other Radiated EMI Sources . . . . . . . . . . . . . 211

10 Box Shielding . . . . . . . . . . . . . . . . . . . . . . . 213

10.1 How to Determine Box Attenuation Requirements . . . . . . . . . 214

10.2 Some Shielding Basics: Shielding Effectiveness

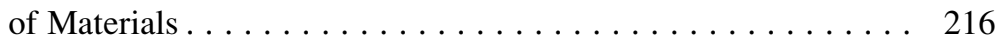

10.3 Shielding Effectiveness of Conductive Plastics . . . . . . . . . . 221

10.4 Field Attenuation Through Apertures . . . . . . . . . . . 223

10.4.1 Attenuation of One Single Aperture . . . . . . . . . . . . 223

10.4.2 Effect of Multiple Apertures Leakages . . . . . . . . . . . . 226

10.5 Alterations of the Ideal "Hole-In-A-Wall" Model . . . . . . . . . . 230

10.5.1 Effect of Source Proximity on Aperture Leakage . . . . . 231

10.5.2 Effect of Box Natural Resonances . . . . . . . . . . . . 232

10.6 Methods of Leakage Reduction and Aperture Treatment . . . . . 233

10.6.1 Mating Panels and Cover Seams . . . . . . . . . . . . . . 234

10.6.2 Shielding for Cooling Apertures . . . . . . . . . . . . . . 240

10.6.3 Shielding for Viewing Apertures . . . . . . . . . . . . . . . . . 242

10.6.4 Shielding the Component Holes . . . . . . . . . . . . . . 244 
10.6.5 Shielding of Cable Penetrations, Connectors, and Nonconductive Feedthroughs . . . . . . . . . . 244

10.6.6 Detrimental Effect of Box Leakages

Near a Cable Penetration . . . . . . . . . . . . . . . 246

10.7 Specially Hardened Equipment Housings . . . . . . . . . . . . . . . 246

10.8 Application Example: Box Design for a Given SE Objective . . . . . . . . . . . . . . . . . . . . . . . . . . . 249

10.9 Shielding Components for Mass-Production of Consumer Products . . . . . . . . . . . . . . . . . . 251

10.10 Summary of Radiation Control via Box Shielding . . . . . . . 252

References.......................... 253

11 Controlling Radiated Emissions at I/O Ports

and External Cables . . . . . . . . . . . . . . . . . . . . . . 255

11.1 Filtering of Input/Output Ports . . . . . . . . . . . . 255

11.1.1 Determining the Cutoff Frequency

of an EMI Filter for Digital Outputs . . . . . . . . . . 256

11.1.2 Determining the Proper EMI Filter Order . . . . . . . . 258

11.1.3 Determining the Proper EMI Filter Type . . . . . . . . 259

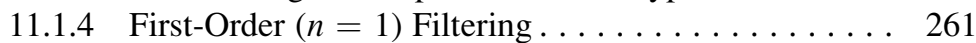

11.1.5 Multi-element Filters Applications . . . . . . . . . . 268

11.1.6 Avoiding the Most Frequent Pitfalls with Multielement Filters . . . . . . . . . . . . . . 269

11.1.7 Special CM Filters for High-Speed Differential Links . . . . . . . . . . . . . . . . . . 273

11.2 Advantages of Balanced Interfaces . . . . . . . . . . . . . . 275

11.3 Line Balancing Devices . . . . . . . . . . . . . . . . 276

11.3.1 Signal Isolation Transformers . . . . . . . . . . . . . . 277

11.3.2 Longitudinal, Non-isolating Transformers . . . . . . . 279

11.4 Reducing CM Radiation by Ferrite Loading . . . . . . . . . . . . . 281

11.4.1 Ferrite-Loaded Cables and Tubing . . . . . . . . . . 287

11.5 Reducing Differential-Mode Radiation by Twisting . . . . . . . . 288

11.6 Reducing Cable Radiation by Shielding . . . . . . . . . . . . 288

11.6.1 Fields Radiated by a Coaxial Cable . . . . . . . . . . 291

11.6.2 Fields Radiated by Shielded Pairs

or Multiconductor Shielded Cables . . . . . . . . . . . . 301

11.6.3 Shielded Flat Cables . . . . . . . . . . . . . . . . . 303

11.6.4 Importance of the Shield Connections . . . . . . . . . 305

11.6.5 Specifying $Z_{\mathrm{t}}$ from a Given Shielding

Effectiveness Objective . . . . . . . . . . . . . . 307

11.7 Discussion Regarding Shielded vs. Unshielded

Twisted Pairs . . . . . . . . . . . . . . . . . 307

11.8 Eliminating Cable Radiation by Fiber Optics . . . . . . . . . . . . 308

References........................... 308 
12 Principal Radiated Emission Specifications

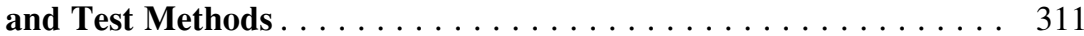

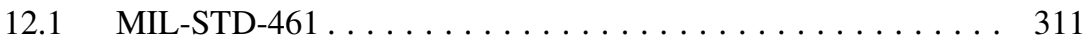

12.1.1 RE101: Magnetic Field, Narrowband (NB),

$30 \mathrm{~Hz}$ to $100 \mathrm{kHz} \ldots \ldots \ldots \ldots \ldots \ldots \ldots \ldots \ldots$

12.1.2 RE102: Electric Field (NB and BB),

$10 \mathrm{kHz}$ to $18 \mathrm{GHz} \ldots \ldots \ldots \ldots \ldots \ldots \ldots$

12.1.3 RE103 Radiated Emissions, Antenna Spurious, and Harmonic Outputs, $10 \mathrm{kHz}$ to $40 \mathrm{GHz}$

(Only for Equipments with RF Functions

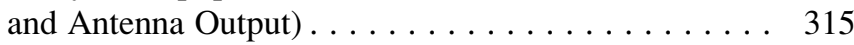

12.2 CISPR International Limits, Test Instrumentation and Methods ...................... 316

12.3 FCC Part 15 Subpart B and Industry Canada . . . . . . . . . . 317

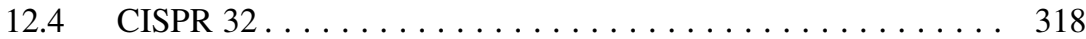

12.5 EN 55014/CISPR $14 \ldots \ldots \ldots \ldots \ldots \ldots \ldots \ldots \ldots \ldots$

12.6 Japan Voluntary Council for the Control of Interference . . . . 320

12.7 CISPR 32 Emission, Multimedia Equipment . . . . . . . . . 320

12.8 FCC Part 18 and EN 55011 (CISPR 11) . . . . . . . . . 321

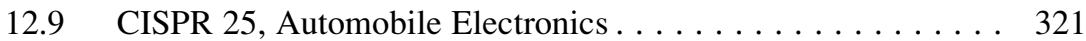

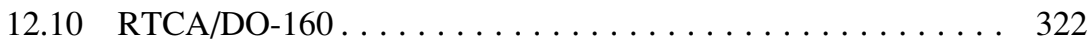

12.11 RE Measurements by the Reverberation

Chamber Method . . . . . . . . . . . . . . . . . . . . . . . . . . . 324

13 Troubleshooting Radiated EMI Problems . . . . . . . . . . . . . 327

13.1 Cable Radiation vs. Box Radiation in Specification Compliance . . . . . . . . . . . . . . . . . . . . . . . . 327

13.2 Strategy When a Product Fails Radiated Emission Tests: Quantifying the $\mathrm{dB}$ Reduction................ 328

13.3 Approximating Radiated RFI Levels from I/O Cable CM Currents (VHF Region) . . . . . . . . . . . . . . . . 335

References.............................. 339

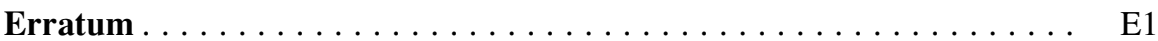

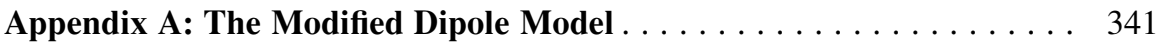

Appendix B: Some Validation Results Supporting the Simplified Radiation Model . . . . . . . . . . . . . . . . 347

Appendix C: Inductances and Capacitances of PCB Traces . . . . . . 351

Appendix D: A Few Equivalent Circuits for Component Modeling via SPICE, MicroCap, or Similar Simulation Tools . . . . 355

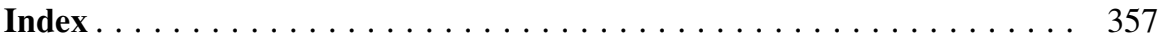




\section{Abbreviations}

$\begin{array}{ll}\text { ACMOS (or ACT) } & \begin{array}{l}\text { Advanced CMOS technology } \\ \text { Advanced low-power Schottky logic }\end{array} \\ \text { BGA } & \text { Ball grid array } \\ \text { BW } & \text { Bandwidth } \\ \text { CISPR } & \begin{array}{l}\text { Comité International Special des Perturbations } \\ \text { Radioélectriques }\end{array} \\ \text { FCC } & \text { Federal Communications Commission (USA) } \\ \text { HF } & \text { High frequency. Although officially used for 3-30 MHz, } \\ & \text { it often designates casually the MHz frequency domain. } \\ \text { LCC } & \text { Leadless chip carrier } \\ \text { LISN } & \text { Line impedance stabilization network (synonymous: } \\ \text { AN } \text { (or LSTTL) } & \text { Low-power Schottky logic } \\ \text { QP } & \text { Quasi-peak } \\ \text { SE } & \begin{array}{l}\text { Shielding effectiveness } \\ \text { SMT }\end{array} \\ \text { SHF } & \text { Uurface-mount technology } \\ \text { VHF } & \text { Very high frequency (30-300 MHz) }\end{array}$





\section{Symbols}

$B$ Magnetic induction, or more exactly flux density (Tesla). In air, $B=\mu_{0} \times H(\mathrm{~A} / \mathrm{m})$

$\beta \quad$ Phase constant $=2 \pi / \lambda$

$\delta \quad$ Skin depth

$\varepsilon \quad$ Electric permittivity constant (for air or free space $=8.85 \times 10^{-12} \mathrm{~F} / \mathrm{m}$ )

$\lambda \quad$ Wavelength $=300 / F(\mathrm{MHz})$

$\mu$ Magnetic permeability (for free space air or nonmagnetic materials $\mu_{0}=4 \pi \times 10^{-7}$ Henry $\left./ \mathrm{m}\right)$

$\phi \quad$ Magnetic flux. In Weber, $\phi=B \times S=$ induction (Tesla) $\times$ area $\left(\mathrm{m}^{2}\right)$

$\omega$ Angular frequency in radians $/ \mathrm{s}=2 \pi \times F$ 